\title{
SIGNIFICADOS SIMBÓLICOS DAS ROUPAS DE FAST FASHION
}

\author{
Symbolic Meaning of Fast Fashion Clothes
}

\begin{abstract}
ALVES, Cristiane Fatima I MBA em Gestão de Varejo e Venda
Universidade Estadual de Maringá - UEM

cristiane.allves@hotmail.com
\end{abstract}

\section{PEPECE, Olga Maria Coutinho}

Universidade Estadual de Maringá - UEM

opepece@gmail.com

\section{Resumo}

O presente estudo teve como objetivo identificar os significados simbólicos que as mulheres atribuem ao consumo de roupas de fast fashion. Foram entrevistadas doze mulheres, entre 20 a 35 anos e de diferentes classes sociais. Os resultados obtidos mostram que as roupas de fast fashion são símbolos de roupas chiques, de estilo high low, de estilo, de novidade, de tendência e de estar na moda gastando pouco.

Palavras chave: Consumo, Roupas de fast fashion, Mulheres.

\section{Abstract}

This study aimed to identify the symbolic meanings of the consumption of fast fashion clothing by women. Twelve women between 20-35 years old and of different social classes were interviewed. The results show that the fast fashion clothing is a symbol of sophisticated clothes, high low style, style, novelty, trend and being fashionable with low expenses.

Keywords: Consumption, Fast fashion clothing, Women. 


\section{INTRODUC̣̃̃O}

Consumir vestuário de moda é consumir algo que está repleto de simbologia, que vai muito além de um pedaço de pano, que é capaz de produzir e transmitir muitos significados ao longo do tempo.

A moda está ficando mais acessível em grande medida em decorrência do vestuário fast fashion. O fast fashion tem características próprias, definidas principalmente pela cultura do local de comercialização dos itens desse perfil. Falando mais especificamente das roupas de fast fashion, essas são encontradas em diversos tipos de lojas, desde aquelas pequenas, tipo boutique, até grandes lojas de departamento. As principais lojas de fast fashion que competem no mercado brasileiro são: Riachuelo, Zara, Renner, Marisa e C\&A (CIETTA, 2012).

Uma pesquisa realizada por uma empresa global de consultoria a Bain\&Co, representada nos quatros continentes, mostrou que o crescimento das empresas de fast fashion ocorreu no início de 2005, tanto em termos de faturamento como em rendimentos, as marcas de fast fashion cresceram, em média de 15 a 20\% a mais do que nos anos anteriores (CIETTA, 2012).

Diante deste contexto, a originalidade desta pesquisa visa ampliar o estudo de um tema pouco explorado, mas que abre diversas oportunidades de estudo sobre a moda fast fashion no Brasil. Reconhecendo a atualidade do tema e a possibilidade de compreender o comportamento e os significados que são construídos em torno do vestuário fast fashion, percebendo como as consumidoras transmitem e reproduzem esses significados no seu contexto social, este artigo tem como objetivo: identificar os significados simbólicos que as mulheres atribuem ao consumo de roupas deste tipo de vestimenta.

\section{REVISÃO DE LITERATURA Cultura e Consumo}

Para Geertz (1989) o conceito de cultura é essencialmente semiótico, o homem é um animal amarrado a teias de significados que ele mesmo teceu, essas teias são a cultura. Essa é a qualidade mais relevante do ser humano e que o difere dos outros animais por ser o único que possui cultura. Por meio da cultura também os bens de consumo adquirem significados, no qual a cultura permite ao homem compreender as relações que existem entre consumo e cultura na sociedade (LARAIA, 2008).

No que diz respeito ao consumo, Rocha e Rocha (2007) abordam o consumo como um sistema de significação, classificação e como código, os 
autores estabelecem que o estudo do consumo, busca captar informações sobre modelos, ideologias, significados coletivos ou percepções em relação aos hábitos de consumo compartilhado e sobre a forma como os produtos/serviços adquirem sentido ao se inserirem em redes de relações sociais.

Portanto, o consumo é influenciado por uma rede de relações sociais, com inter-relações que poderiam se estender ao longo do tempo, sendo assim, o consumo está intimamente ligado à renda, à história familiar, ao país de origem, à profissão, à região onde mora e ao estilo de vida. (CRUZ, 2008).

Sob essa perspectiva, Barbosa e Campbell (2006) afirmam que a relação entre cultura e consumo é complexa para análise. Segundo estes autores, os bens de consumo podem exercer inúmeros papéis, como por exemplo, medir as relações sociais e construir identidades. O que se vê, portanto, é que a oportunidade de expressar os anseios individuais, por meio dos bens de consumo, influencia o processo de construção da identidade e subjetividade dos consumidores.

Portanto, ao tratar de aspectos que relacionam cultura e consumo, é possível analisar como os indivíduos são estimulados a consumir de acordo com os significados simbólicos que percebem e atribuem ao ato de consumir. Por isso, faz-se necessário entender como os indivíduos manifestam determinadas opções e a que atribuem a escolha de determinado produto (CRUZ et al, 2012), uma vez que o comportamento do consumidor não é orientado somente pelos aspectos funcionais dos produtos, mas também pelos seus mais diversos significados sociais.

\section{Consumo Simbólico}

Slater (2002) e Barbosa (2004) afirmam que todo o consumo é cultural, já que está carregado de significados que foram compartilhados socialmente. Segundo Slater (2002), ao consumir o indivíduo reproduz seu sistema de relações sociais.

Dentro dessa temática, Slater (2002, p. 132), complementa que "[...] o aspecto significativo ou cultural do consumo passa a predominar, e as pessoas passam a se preocupar mais com os significados dos bens do que com seu uso funcional para satisfazer uma necessidade básica [...]". Desta maneira, é difícil imaginar qualquer sociedade na qual os bens sejam puramente materiais e sem significados simbólicos.

Para Rocha (2000, p. 25) o "[...] consumo começa pela construção de 
um sistema simbólico que permite a circulação de significados, algo capaz de dar significado à esfera da produção". A partir do momento que o consumo é visto como um sistema de significação, a principal necessidade social que supre é a simbólica. Então, se pode dizer que o consumo é como um código, por meio do qual a cultura traduz grande parte das relações sociais. Desta tradução forma-se um sistema de classificação de indivíduos e grupos, coisas e pessoas, produtos e serviços (ROCHA; BARROS, 2004).

Barbosa e Campbell (2006) concluem que o produto funciona como produtor de sentidos e de identidades que situam o consumidor em diferentes grupos sociais, para definir diversas situações em termos de direitos, estilo de vida e identidades na sociedade contemporânea. De fato, os produtos possuem significados de consumo diferentes para grupos diferentes, por isso entender os significados que estão por trás do consumo e como estes significados são interpretados, formados e mantidos, é importante para compreender o processo de transferência dos significados.

\section{Processo de transferência dos significados}

Para McCracken (2003) o significado parte de um mundo culturalmente constituído e se transfere para o bem de consumo, na sequência, este significado se afasta do objeto e se transfere para o consumidor individual. $\mathrm{O}$ próprio autor propõe um modelo de transferência de significados que pode ser visualizado na figura 1, no qual existem três localizações para o significado: o mundo culturalmente constituído, o bem de consumo e o consumidor individual, movendo-se em dois momentos: do mundo para o bem e do bem para o indivíduo.

Figura 01 - Movimento do significado

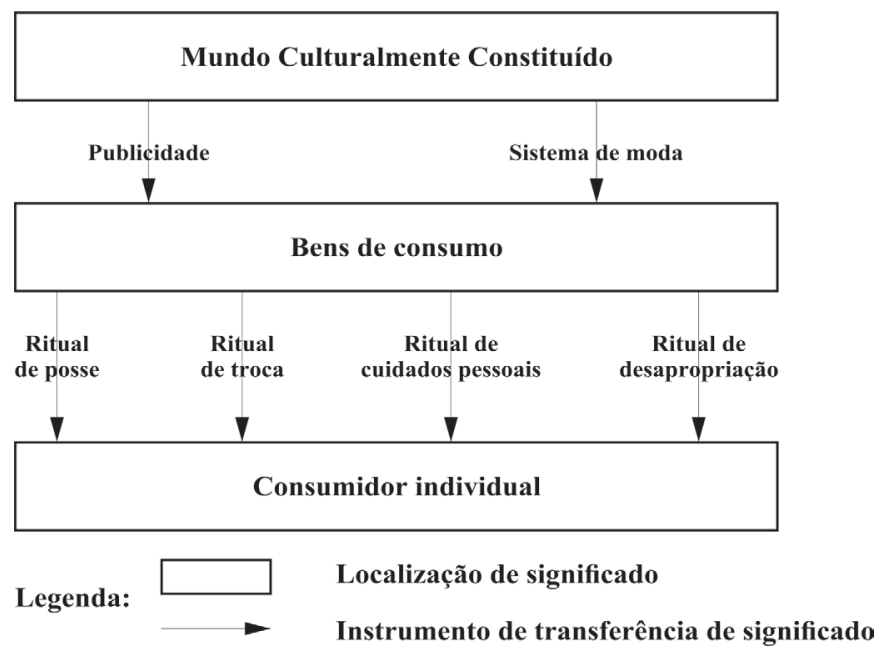

Fonte: McCracken (2003, p. 100). 
Para que o significado se torne inerente aos bens de consumo, ele precisa se deslocar do mundo e transferir-se para o bem. Isso é possível através de dois meios de transferência: a publicidade e o sistema de moda (MCCRACKEN, 2003). A publicidade é um método de transferência de significado nos bens de consumo, esses significados são fontes renováveis como a propaganda mostra todos os dias. (SLATER, 2002). Já o sistema de moda funciona como instrumento de movimentação de significado, atuando de três modos distintos para transferir os significados dos bens: a primeira capacidade refere-se à transferência dos significados do mundo constituído para os bens, ou seja, através de revistas especializadas e desfiles; a segunda inventa novos significados para os bens, neste caso, os líderes de opinião; e por fim, a terceira capacidade além trazer novos significados aos bens, é também responsável pela mudança radical dos significados culturais, pela ação dos grupos inovadores como hippies e punks (MCCRACKEN, 2003).

O que se vê, portanto, é o movimento do significado do mundo constituído para os bens de consumo, em um segundo momento, a transferência de significados dos bens de consumo para o consumidor pode ser considerada um ritual. Douglas e Isherwood (2006) complementam que os rituais são de suma importância, pois os bens servem para fixar significados. O ritual é usado para transferir o significado dos bens para os indivíduos, de acordo com o modelo apresentado por Mccracken (2003) na figura 1, o autor destaca quatro tipos diferentes de rituais: os rituais de troca; de posse; de cuidados pessoais; de despojamento.

Os rituais de troca são usados para direcionar bens carregados de certas propriedades simbólicas para o indivíduo, como por exemplo na troca de presentes, na qual o presenteador escolhe determinado presente porque este possui propriedades simbólicas significativas que ele deseja transferir para o receptor do presente (MCCRACKEN, 2003).

No ritual de posse os indivíduos transferem os significados dos bens para suas vidas, por meio da posse de algo, extraindo as qualidades que the foram conferidas pelas forças de marketing (MCCRACKEN, 2003), como por exemplo alguém se sentir mais bonito por estar usando uma roupa da moda.

Os rituais de cuidados pessoais são utilizados para efetivar a transferência contínua de propriedades especiais e perecíveis que residem em certas roupas, penteados e looks, que serão transmitidas para fora dos bens que lhe servem de suporte. Já o ritual de despojamento diz respeito a esvaziar o significado dos bens, a fim de evitar que a perda de significado ou contágio de significado possa ocorrer (MCCRACKEN, 2003), como quando alguém descarta uma peça do guarda-roupa por acreditar que aquela peça, que outrora era adequada para ir 
ao trabalho hoje não lhe cai bem.

Portanto, entender como se dá o processo de transferência dos significados no mundo dos bens, e como os bens transportam esses significados para o consumidor, se faz necessário, para compreender as propriedades simbólicas que estão por trás dos bens de consumo e ampliar o conhecimento sobre diversas áreas do consumo, neste trabalho especificamente sobre o consumo de roupas de fast fashion.

\section{Consumo de roupas de fast fashion}

Ao vestir-se o indivíduo inicia um processo de comunicação, assim, percebe-se que a moda é um meio de comunicação não-verbal, a roupa não fala, mas expressa muitas coisas, diversos são os códigos das roupas que, ao serem decifrados, são capazes de transmitir informações (OLIVEIRA, 2014).

A maneira de vestir-se vai se modificando conforme o tempo vai passando e esse é um dos fatores que provoca o movimento cíclico da moda (LIPOVETSKY, 1989). Como destacam Garcia e Miranda (2005, p. 110) "a moda é um fenômeno cíclico temporário, adotado por consumidores em tempo e situações particulares". Freitas (2005, p. 135) complementa afirmando que "tudo é muito efêmero, sobretudo a moda. E é exatamente por causa deste caráter provisório da moda que ela se constitui e se insere constantemente num processo de renovação de si mesma". Um bom exemplo dessa renovação é o fast fashion, o qual pode ser considerado um fenômeno da moda atual que veio para acompanhar a cabeça do consumidor, num mundo globalizado em que a informação é absorvida de forma muito rápida. O modelo fast fashion acompanha os desejos de consumo dos consumidores que buscam estar na moda juntamente com o aparecimento das tendências (CIETTA, 2012).

Segundo Cietta (2012) O sucesso das empresas de fast fashion se deu, provavelmente, pelo fato delas desenvolverem a capacidade de oferecer, em curto prazo, aquilo que o mercado anseia, pois a velocidade de resposta é muito rápida, o tempo para produzir uma nova coleção nos últimos anos caiu de vinte quatro meses para poucas semanas. Logo, o modelo fast fashion oferece um novo conceito de produção de moda com redução do tempo de preparação e produção, para que as peças cheguem às lojas em poucas semanas. Por outro lado, a indústria da moda está acostumada a apresentar seus produtos organizados em coleções distribuídas ao longo do ano, de acordo com as estações, estabelecendo duas ou quatro coleções anuais.

Dentro deste contexto, as empresas de roupas fast fashion levam a moda, 
em muitos casos, a preços acessíveis às pessoas e oferecem diversidade de vestuário (CIETTA, 2012).

Cabe ressaltar também, as parcerias que as empresas de fast fashion tem feito nos últimos anos, com estilistas emergentes ou já renomeados. Com essas parcerias os consumidores podem comprar as peças que levam as assinaturas destes estilistas por um preço muito inferior do que o encontrado nas suas grifes de origem (SAPPER, 2011; CIETTA, 2012).

O nível de informação que as empresas de fast fashion possuem é muito alto, elas se baseiam em tendências que, em sua maioria, já estão firmadas, assim é possível fazer uma análise mais concreta do que irá funcionar ou não das novidades a serem lançadas (SAPPER, 2011). As empresas que praticam fast fashion também investem em criatividade, desenvolvendo coleções próprias com sua marca e estilo. Suas fontes de inspiração estão relacionadas a estereótipos de beleza, elegância e feminilidade construídos pela mídia e sua criatividade é baseada em construir coleções mais eficazes para o mercado. Desta forma, as empresas reproduzem roupas de grifes que aparecem nas semanas de moda internacionais ou nacionais e nas revistas de moda, reproduzindo um padrão mundial ligado à estética dos editoriais de moda das grandes revistas do setor (MESSIAS, 2012).

Por fim, o comportamento de consumo de moda pode ser entendido pela necessidade de expressar significados mediante a posse de objetos que comunicam à sociedade de que forma o indivíduo se percebe e se relaciona com grupos sociais (GARCIA; MIRANDA, 2005). Harvey (2003, p. 17) conclui ao dizer que "estar na moda é sempre um momento dentro de um movimento, e as maiores mudanças nas roupas são indícios de mudança na sociedade". Assim, ao se apropriar de um bem que carrega signos referentes à moda, o indivíduo faz associações em torno de seu consumo.

\section{PROCEDIMENTOS METODOLÓGICOS}

Para o desenvolvimento deste artigo foram realizadas entrevistas previamente agendadas, gravadas e posteriormente transcritas. As entrevistas ocorreram tanto na residência, como no local de trabalho ou de estudo das entrevistadas e para encontrá-las foi utilizada a técnica de bola de neve (MALHOTRA, 2011).

Foram realizadas entrevistas com doze mulheres, na faixa etária compreendida entre 20 a 35 anos. Quanto à classe socioeconômica das entrevistadas, foram sete mulheres da classe $A$, duas da classe $C 2$, duas da 
classe B1 e uma da classe B2, de acordo com critério de Classificação Econômica Brasil (ABEP, 2013). De acordo com os critérios estabelecidos no protocolo da pesquisa, os nomes das entrevistadas foram omitidos por questões éticas e, portanto, no decorrer da análise as mulheres foram identificadas por letras do alfabeto, conforme o quadro 1.

Quanto à análise dos dados, optou-se pelo método da análise temática que o "[...] produto final constitui uma interpretação das entrevistas, juntando estruturas de relevância dos informantes com as do entrevistador [...]" (JOVCHELOVITCH; BAUER, 2002, p. 107).

\section{ANÁLISE DOS DADOS}

No quadro 01 encontram-se o perfil socioeconômico das entrevistadas, e a forma como elas serão identificadas no estudo.

Quadro 01 - Perfil das entrevistadas

\begin{tabular}{|l|l|l|l}
\hline Código & Atividades \\
\hline A & $\begin{array}{l}30 \text { anos, casada, não tem filhos, possui superior incompleto. Trabalha } \\
\text { como maquiadora e vendas diretas de produtos da Mary Kay. }\end{array}$ \\
\hline B & $\begin{array}{l}23 \text { anos, solteira, estudante do curso Moda, no momento não atua na } \\
\text { área. }\end{array}$ \\
\hline C & $\begin{array}{l}32 \text { anos, casada, um filho, trabalha na Universidade Estadual de Maringá } \\
\text { como professora. }\end{array}$ \\
\hline D & 21 anos, solteira, profissão estudante, cursando o ensino superior. \\
\hline G & $\begin{array}{l}21 \text { anos, solteira cursando nutrição na PUC- Maringá. } \\
\text { um shopping da cidade. }\end{array}$ \\
\hline E & \begin{tabular}{l} 
Mestrado em Administração. \\
\hline
\end{tabular} \\
\hline
\end{tabular}


26 anos, solteira, segundo grau completo e trabalha com gerente de vendas em uma loja localizada no Shopping Catuaí Maringá.

30 anos, casada, um filho, superior incompleto e trabalha como Gerente de uma loja de sapatos localizada em um shopping da cidade.

\begin{tabular}{|l|l|}
\hline K & $\begin{array}{l}24 \text { anos, solteira, atua como freelancer de produção de moda e está } \\
\text { cursando Mestrado em Administração. }\end{array}$ \\
\hline L & $\begin{array}{l}32 \text { anos, casada, não tem filhos, superior com completo com MBA em } \\
\text { moda e atua como consultora de moda. }\end{array}$ \\
\hline
\end{tabular}

Fonte: Elaborado pelos autores.

\title{
Fast Fashion e a construção dos significados
}

Antes de compreender os significados simbólicos que as consumidoras de roupas de fast fashion atribuem a este tipo de produto, é necessário entender as percepções que elas têm sobre a moda fast fashion.

\begin{abstract}
Um movimento que trabalha a informação de moda para ser utilizada somente num período determinado de tempo, então a ideia de você ter um objeto ou informação que segue uma tendência direcionada diretamente neste caso para um produto de vestuário e que ela é para ser usada naquele período somente de duração da estação normalmente (ENTREVISTADA E, 32 anos, classe B1).
\end{abstract}

Eu acredito que o fast fashion seja a moda rápida, as lojas atendendo a demanda de forma rápida que são as trocas constantes seguindo as tendências e seguindo a lei do consumo do consumidor, o tanto que ele consome e o que vende mais rápido tem mais loja, e as lojas de fast fashion seguem essa demanda, quanto mais vendem eles procuram oferecer isso ao público eu acredito que seja, e também de fácil acesso para todos (ENTREVISTADA D, 23 anos, classe B2).

Isso confirma o que Samara e Morsch (2005) trazem de que a cultura é acumulação de valores, costumes, conhecimento e conceitos que evoluem por meio de comportamentos e símbolos significativos que as pessoas usam para se comunicar, interpretar e avaliar o contexto no qual elas estão inseridas. 
Uma vez entendido que essas mulheres possuem entendimento compartilhado do que seja fast fashion, faz-se necessário entender como as pessoas manifestam determinadas opções e a que atribuem a escolha de determinado produto (CRUZ et.al, 2012). A seguir apresentam-se as falas das entrevistadas sobre as referências que elas têm sobre o que é ser uma consumidora de fast fashion. As repostas foram unânimes para as dozes entrevistadas.

Acho que não tem nenhuma diferença de outras marcas, outras formas, talvez sejam outros que olhem isso como predatório não se importa, eu acredito que ser consumidora de fast fashion é mais você está na velocidade da informação, na velocidade que as coisas acontecem então você está inserida dentro dessa novidade constante (ENTREVISTADA E, 32 anos, classe B1).

Eu acho que a gente sempre fica procurando as tendências, vendo o que as pessoas estão usando para tentar manterse nesse universo, eu sempre pesquiso muito na internet fico sempre olhando as coisas, as lojas que me interessam, sempre quando tem algum comercial eu tento dar uma olhada. Ser uma consumidora é essa ideia de estar buscando o novo, a novidade, o atual (ENTREVISTADA C, 32 anos, classe $A$ ).

Além disso, todas as entrevistadas disseram que são altamente envolvidas com as roupas de fast fashion, por terem período longo de consumo e pela forma como trabalham a informação de moda. Conforme ilustra a fala da entrevistada a seguir:

No segmento fast fashion eu tenho algumas peças que já tem cinco anos, então eu acho que depende de como a gente escolhe dentro da marca da loja ou da empresa para utilizar, mais em média eu acho que deve dar, se for as peças mais básicas, um ano ou estação, talvez entre quatro a seis meses, porque tem peças com eu disse eu gosto de blazer, são contexto de alfaiataria eu não vou jogar fora na outra estação, por exemplo, eu tenho um que ele é estampado com estampa daquela estação então, vai muito do estilo de cada um de utilizar e coordenar isso com outras peças, mesmo que não seja tendência, ele acabou durando mais por conta da minha forma de trabalhar essa informação de moda (ENTREVISTADA E, 32 anos, B1). 
Como lembra Barbosa (2004), o consumo é cultural, uma vez que funciona como parte da construção e afirmação de identidades, diferenciação, exclusão e inclusão social que media relações e práticas sociais. Para a autora, a relação entre cultura e consumo, possibilita compreender o consumo como um processo social que produz sentidos e identidades, independentemente da aquisição de um bem.

Dentro deste contexto, as entrevistadas não possuem preconceito e não se intimidam em falar que compram e usam roupas de lojas fast fashions de preço acessível.

\begin{abstract}
As pessoas às vezes perguntam o que eu estou usando, às vezes acontece, por exemplo, "que lindo, onde você comprou?" comprei em tal loja, não tem problema de falar que foi em fast fashion barata, nada disso, porque é o meu estilo (ENTREVISTADA K, 24 anos, classe A).
\end{abstract}

O que se vê, portanto, no relato acima, de acordo com Barbosa e Campbell (2006) é a oportunidade de expressar os anseios individuais por meio dos bens de consumo que influenciam no processo de construção da identidade das consumidoras. O relato da entrevistada aponta que ela busca consumir muito mais do que roupas de fast fashion, por meio desse tipo de roupa. Ela busca afirmar a sua identidade, mostrar que está inserida no contexto no que diz respeito à moda, por isso, se faz importante compreender mais profundamente o comportamento de consumo dessas consumidoras.

\title{
Aspectos culturais e simbólicos das roupas de fast fashion
}

Nas lojas de fast fashion são vendidos todos os tipos de vestuário, porém o que mais atrai as entrevistadas são blusas, blazer, shorts e vestidos, porque essas peças sempre são atualizadas em todas as coleções com estampas, modelos e cores diferentes. Como observa-se nas falas a seguir.

\section{Tipo de peças:}

O que eu compro mais são blusas, por conta da facilidade de justamente de você está atualizando, trocando, parece que você sempre está com uma roupa nova, você coloca um jeans e coloca blusas diferentes, as pessoas nem vão perceber que você está com o mesmo jeans, mais com blusas diferentes, então eu acho que são blusas que eu compro mais eu gosto bastante de blusas (ENTREVISTADA 


\section{C, 32 anos, classe A).}

Bom, ai entra o contexto do que eu gosto, eu adoro blazer, sou apaixonada por blazer, se eu tiver a chance de comprar um blazer eu compro. E outras peças que eu sei que aquela estampa vai usar, as cores da estação, daí como eu trabalho com moda, eu sempre penso essa da para usar talvez lá na frente, a gente tenta, mais é seduzida pela estampa que é mais chamativo, mas a parte de cores principalmente (ENTREVISTADA E, 32 anos, classe B1).

A partir das falas das entrevistadas acima, o consumo tem sido utilizado de diversas formas, para comunicar significados culturais, para suprir necessidades físicas e emocionais, para se relacionar com outros e para afirmar a própria identidade, desta forma, as pessoas não compram os produtos somente pelo que eles são capazes de fazer, mas por tudo que eles podem significar (FERLA; SILVEIRA, 2008). A partir do momento que o consumo é visto como um sistema de significação, a principal necessidade social que supre é a simbólica (ROCHA, 2000).

Como já citado por Sapper (2011) e Cietta (2012) as lojas de fast fashion possuem um ciclo muito rápido de troca, no qual a cada três meses a coleção é mudada completamente, desenvolvendo mini-coleções e também oferecendo às consumidoras toda semana uma peça nova. Isso faz com que as consumidoras aumentem sua frequência de compra.

\section{Frequência de compra:}

Bom eu comprou a cada três meses mais ou menos, porque é a periodicidade que eles fazem o lançamento na loja, então eu volto cada vez que tem coisa nova na loja, embora pequenos lançamentos aconteçam toda semana (ENTREVISTADA E, 32 anos, classe B1).

Uma vez por mês. Mais eu tenho as comprinhas planejadas que determinadas épocas do ano que têm os lançamentos legais, que eu fico de olho nas passarelas internacionais mais também têm aquelas comprinhas do que eu vou usar na semana (ENTREVISTADA K, 24 anos, classe A).

Quando questionadas sobre gasto médio com roupas de fast fashion as respostas das entrevistadas foram praticamente unânimes, elas admitiram gastar especificamente com roupas de fast fashion mais de duzentos reais por 
mês, mas que esse valor depende muito das peças, pois o fast fashion oferece roupas baratas e caras, como Cietta (2012) afirma na revisão apresentada.

\section{Gasto:}

Em média daria entre 300 reais, às vezes um pouco menos às vezes um pouco mais depende da peça, então acabaria dando talvez até cem reais por mês com Fast Fashion se fosse diluir (ENTREVISTADA E, 32 anos, classe B1).

Depende do mês, depende da coleção e do produto. Tem mês que chega a duzentos reais tem mês que passa, varia bastante (ENTREVISTADA H, 25 anos, classe C2).

Barbosa e Campbell (2006) afirmam que o produto funciona como produtor de sentidos e de identidades que situa o consumidor em diferentes grupos sociais para definir diversas situações em termos de direitos, estilo de vida e identidades na sociedade contemporânea. As entrevistadas afirmaram que as roupas de fast fashion não têm uma ocasião específica para serem usadas, as roupas de fast fashion se encaixam em todas as ocasiões do trabalho à festa, dia ou noite, o importante é a roupa estar de acordo com o estilo da entrevistada e ocasião de uso.

\section{Ocasiões:}

Faculdade, supermercado, no dia a dia mesmo. (ENTREVISTADA G, 21 anos, classe B1).

No meu dia a dia, acho que o tempo inteiro, porque faz parte do estilo, não é algo assim que eu separe isso é fast fashion, que eu vou usar só para uma ocasião. Se eu gosto daquilo é algo que eu vou usar em qualquer ocasião, por exemplo, André Lima que foi uma coleção da Riachuelo ano passado, eu uso em eventos (ENTREVISTADA K, 24 anos, classe A).

\section{Processo de transferência dos significados simbólicos atribuídos ao consumo de roupas fast fashion}

Foram identificados seis significados simbólicos atribuídos ao consumo de roupas fast fashion, sendo eles - chique, estilo high low, estilo, novidade, tendência e estar na moda com preço acessível. Os significados não estão relacionados em ordem de relevância, mas estão elencados conforme foram 
aparecendo ao longo das entrevistas.

Chique: Este significado encontrado nos relatos das entrevistadas está relacionado ao entendimento que as mulheres têm sobre moda. Conforme relatam as consumidoras:

Faz a gente se sentir um pouco chique, aquela sensação de sentir chique, mais atualizada como atrizes essas coisas, mas não no mesmo nível (...) (ENTREVISTADA D, 21 anos, classe B2).

[...] pode ficar tão chique e elegante quanto alguém que pode comprar a roupa do estilista mesmo (ENTREVISTADA J, 30 anos, classe $\mathrm{A}$ ).

A partir dos relatos das consumidoras é possível compreender o que McCracken (2003) diz quando afirma que a experiência cotidiana possibilita a construção de novos significados que são moldados e construídos pelas crenças e pressupostos da cultura. Portanto, neste contexto, o sistema de moda funciona como instrumento de movimentação do significado pelo qual uma das suas capacidades é a de criar novos significados.

Estilo High Low: Para maioria das consumidoras as roupas de fast fashion podem ser vistas como uma compra inteligente, pois é por meio delas que essas consumidoras absorvem as tendências e trazem para sua realidade montando produções de acordo com seu gosto. Os relatos a seguir expressam bem este significado:

[...] gosto muito do look high low, essa coisa de você poder usar uma peça super cara com uma super barata, quebra um pouco daquela coisa, para você se vestir bem tem que vestir peças caras ou peças de valor elevado para sua condição, acho isso totalmente passado (ENTREVISTADA K, 24 anos, Classe A).

Eu gosto de comprar uma peça de fast fashion que tem um preço bacana e pode representar isso para pessoas misturando com alguma peça de grife, isso dá um visual legal. (ENTREVISTADA L, 32 anos, classe A).

Estilo: A roupa fast fashion se tornou um código na vida das consumidoras capaz de transmitir estilo através das roupas, isso está diretamente ligado ao 
que Oliveira (2014) diz a respeito da moda como meio de comunicação não verbal e ao fato da roupa expressar diversos códigos, que quando interpretados podem ser compreendidos, conforme os relatos a seguir:

Prefiro pinçar o meu estilo, eu não vou pelo fato de ser tendência, tem a ver com meu estilo, ótimo. A minha relação é estritamente buscar o meu estilo no que está dentro das tendências tentando manter qualidade e o preço. Quando visto uma peça eu quero transmitir o meu estilo, o meu estilo de vida através das minhas roupas, a minha personalidade (ENTREVISTADA B, 23 anos, classe A).

Meu estilo, minha personalidade, eu tento fazer encaixar bem comigo, (...) porque acompanha muito a minha personalidade que é totalmente eclética (ENTREVISTADA F, 23 anos, classe (2).

Novidade: A moda renova-se continuamente e movida pelo gosto das novidades e pela busca das coisas novas da moda, e isso provoca o consumo de mais e novos vestuários (COUTINHO, 2008). Nos relatos a seguir este significado fica bem evidente:

É justamente a ideia da novidade, sempre parecer que tem coisas novas na questão de modelo, cores, (...) cortes diferentes. Sempre estou procurando ver o que tem de diferente. Então eu acho que é a ideia da novidade do atual da moda (ENTREVISTADA C, 32 anos, classe A).

No fast fashion toda semana tem uma novidade, não aquele tipo de loja que você entra e tem aquela coleção toda e aquela coleção vai permanecer, por exemplo, o verão todo. Nas lojas fast fashion toda semana que você vai à loja tem uma novidade, então tem sempre uma coisa nova para você usar (ENTREVISTADA J, 30 anos, classe A).

Tendências: As lojas de fast fashion possuem um nível de informação muito alto para desenvolver suas coleções, pois as empresas de fast fashion não têm uma coleção totalmente pronta a cada temporada. Essas coleções são desenvolvidas de acordo com as tendências de moda, referências dos desfiles das semanas de moda internacionais e nacionais e outras referências como os figurinos das novelas (STEFFEN, 2005), aqui no Brasil. Para entender melhor este significado as entrevistadas colocam que: 
Eu acredito que é uma das maneiras que a gente tem acesso mais rápido a informação de moda e tendências, isso facilita até o contexto de aquisição de produtos que eu não poderia ter talvez das marcas que lançaram e utilizaram aquela informação de tendência, mas eu tenho uma forma produzida com menor custo e com alguma referência e ao mesmo tempo você continua antenada com essa informação de moda (ENTREVISTADA E, 32 anos, classe B1).

As roupas de fast fashion sempre estão com as últimas cores, modelos que estão usando no momento as últimas tendências, acho que isso, você quer ter aquela peça já (ENTREVISTADA J, 30 anos, classe A).

Vestir bem com preço acessível e na moda: Este significado foi um dos mais mencionados pelas entrevistadas, porque apesar das roupas serem compradas em lojas fast fashion, para essas mulheres é possível expressar para sociedade que pode vestir-se bem com roupas de fast fashion.

Eu acredito que hoje em dia a gente não precisa ter muito dinheiro para estar bem vestida e estar na moda, basta você querer se informar e ir atrás, pois tem lojas com preços acessíveis com peças muito bonitas. [...] e é fácil hoje em dia estar bem vestida e na moda para nós está de fácil acesso isso, independente de caráter financeiro, está fácil hoje em dia (ENTREVISTADA D, 21 anos, classe B2).

A partir do relato anteriormente citado é possível perceber que nem sempre estar com uma roupa cara significa vestir bem, o que importa para essas mulheres é o prazer de sentir-se bem por estar bem vestida e na moda. Este relato confirma os achados de Garcia e Miranda (2005) ao afirmarem que as mudanças de significados das roupas são indícios de que está havendo uma mudança na sociedade, pois a consumidora ao se apropriar de um bem que carrega significados relacionados à moda faz associações em torno do seu consumo.

Os relatos das entrevistadas aqui apresentados também comprovam as ideias de Cietta (2012) de que a alta moda deve muito ao fast fashion, pois o fast fashion permitiu uma maior difusão do aprendizado sobre o vestir-se bem mais elevado do que a alta costura. 


\section{CONSIDERACÕ̃ES FINAIS}

Conclui-se que as roupas fast fashion exercem um papel fundamental no processo de construção dos significados por meio do vestir, as consumidoras absorvem o filtro da interpretação de moda que as lojas de fast fashion produzem e, através desse produto de consumo, as mulheres reafirmam sua identidade, criam seu estilo e definem sua personalidade. De fato, as roupas de fast fashion estão presentes na vida de muitas mulheres e se encaixam no seu estilo de vida.

Por meio deste estudo foi possível constatar que as primeiras revelações sobre as percepções que as mulheres têm sobre moda fast fashion são aspectos culturais em relação ao tipo de roupa, frequência de compra e ticket médio de compra.

Enfim, para as consumidoras de fast fashion essas roupas são símbolos de roupas chiques, estilo high low, estilo, novidade, tendência e estar na moda com preço acessível. Isso mostra como o sistema de moda funciona como instrumento de movimentação do significado. Por este motivo, os profissionais que desenvolvem produtos de fast fashion devem estar sempre atentos para a função de transmissão de significados que esses produtos possuem, devendo fazer uso de processos criativos que mantenham essa característica que é tão valorizada pelas consumidoras de fast fashion.

Para futuras pesquisas sobre o tema seria interessante investigar os significados atribuídos pelas camadas de baixa renda sobre o consumo de fast fashion e verificar se esses significados são similares ou distintos dos encontrados em classes mais altas.

\section{REFERÊNCIAS}

ABEP. Associação Brasileira das Empresas de Pesquisa. Disponível em: <http://www.abep.org.br> Acesso em: 20 jul. 2013.

BARBOSA, L.; CAMPBELL, C. Cultura, consumo e identidade. Rio de Janeiro: FGV, 2006.

BARBOSA, Lívia. Sociedade de consumo. Rio de Janeiro: Jorge Zahar Ed, 2004.

CIETTA, Enrico. A revolução do Fast-Fashion: Estratégias e modelos organizativos para competir nas indústrias híbridas. 2. ed. São Paulo:

Estação das Letras e Cores, 2012. 
COUTINHO, Fernanda Gabriela Andrade. Moda: efemeridade, consumo e comunicação. Revista UNIFAMMA, Maringá, v.7, n.1, p. 7-37, nov. 2008.

CRUZ, R. C. O consumo a Partir da Lógica do Consumidor: Usando o Arcabouço das Representações Sociais. In: ENANPAD - NACIONAL DOS PROGRAMAS DE PÓS-GRADUAÇÃO EM ADMINISTRAÇÃO, 2008, Rio de Janeiro, 2008.

CRUZ, Z. G.; AUGUSTO, C. A.; VIEIRA, F. G. D.; NATT, E. D. M. O Processo de transferência de Significados: Um Estudo Sobre o Consumo Simbólico de Lingerie por Mulheres de Baixa Renda. Revista Comunicação Mídia e Consumo, São Paulo, v.9, n.25, p. 141-178, ago. 2012.

DOUGLAS, M.; ISHERWOOD, B. O mundo dos bens: para uma antropologia do consumo. Rio de Janeiro: UFRJ, 2006.

FERLA, Diego Alexsander; SILVEIRA, Teniza. A Relação entre os Benefícios Simbólicos do Consumo e a Formação da Identidade dos Jovens Consumidores através de uma Abordagem Metodológica Mista. In: EMA - ENCONTRO DE MARKETING DA ANPAD, 2008, Curitiba.

FREITAS, Ricardo Ferreira. Comunicação, consumo e moda: entre os roteiros das aparências. Comunicação, mídia e consumo. São Paulo, v. 4 n. 2, p. 125-136, 2005.

GARCIA, Carol; MIRANDA, Ana. Moda é comunicação: experiências, memórias, vínculos. São Paulo: Anhembi Morumbi, 2005.

GEERTZ, C. A interpretação das Culturas. Rio de Janeiro: Guanabara, 1989.

HARVEY, John. Homens de preto. São Paulo: Editora UNESP, 2003.

JOVCHELOVITCH, S.; BAUER, M. W. Entrevista narrativa. In: BAUER, M. W.; GASKELL, G. Pesquisa qualitativa com texto, imagem e som: um manual prático. Petrópolis: Vozes, 2002.

LARAIA, R. de B. Cultura: um conceito antropológico. 22. ed. Rio de Janeiro: Zahar, 2008. 
LIPOVESTSKY, Gilles. O império do efêmero: a moda e seu destino nas sociedades modernas. Tradução de Maria Lúcia Machado. São Paulo: Companhia das Letras, 1989.

MALHOTRA, Naresh. Pesquisa de Marketing: uma orientação aplicada. 3. ed. São Paulo: Bookman, 2011.

MCCRACKEN, G. Cultura e consumo: novas abordagens ao caráter simbólico dos bens e das atividades de consumo. Rio de Janeiro: MAUD, 2003.

MESSIAS, Elizete Menezes. As lojas populares e a comercialização da elegância. In: SIEP - SEMINÁRIO INTERNACIONAL DE ESTUDOS E PESQUISAS EM CONSUMO, 2., 2012, São Paulo. Anais... São Paulo, 2012.

OLIVEIRA, Cristiano. Moda como ferramenta de cultua visual. Disponível em: <http://www2.uol.com.br/modabrasil/leitura/moda_cultura_ visual/>. Acesso em: 11 Mar. 2014.

ROCHA, A da; ROCHA, E. Paradigma interpretativo nos estudos do consumo: retrospectiva, reflexões e uma agenda de pesquisas para o Brasil. Revista de Administração de Empresas, São Paulo, v. 47, n. 1, jan./ mar. 2007.

ROCHA, Everaldo; BARROS, Carla Fernanda. Dimensões Culturais do Marketing: Teoria Antropológica, Estudos Etnográficos e Comportamento do Consumidor. In: ENANPAD -ENCONTRO DA ANPAD, 2004, Curitiba, 2004.

ROCHA, E. Totem e consumo: um estudo antropológico de anúncios publicitários. Revista ALCEU (PUC-RIO), Rio de Janeiro v.1, n.1, jul./dez. 2000.

SAMARA, Beatriz Santos; MORSCH, Marco Aurélio. Comportamento do consumidor: conceitos e casos. São Paulo: Pearson Prentice Hall, 2005.

SAPPER, Stella L. Consumo: a engrenagem do fast fashion. Revista da Pesquisa, Florianópolis, n.8, ago.-jul. 2011.

SLATER, D. Cultura, consumo e modernidade. São Paulo: Nobel, 2002.

STEFFEN, Daniela. A influência dos figurinos de novela na moda 
brasileira. In: CONGRESSO BRASILEIRO DE CIÊNCIAS DA

COMUNICAÇÃO, 28., 2005, Rio de Janeiro. Anais... Rio de Janeiro, 2005.

Recebido em:04/04/14

Aprovado em:22/06/14 